Robert D. Montoya and Gregory H. Leazer. 2019. Public Knowledge, Private Ignorance, and an Analytic of Knowledge Organization. NASKO, Vol. 7. pp. 174-182.

Robert D. Montoya - Indiana University, Bloomington

Gregory H. Leazer - University of California-Los Angeles

\title{
Public Knowledge, Private Ignorance, and an Analytic of Knowledge Organization
}

\begin{abstract}
Patrick Wilson's writings have proven to be the foundation for much of our thinking about the organization of documents and their subtle connection to power structures that govern their construction and use. His examinations of public versus private knowledge, for example, expand how we understand individual and social epistemology within the field. In his writings, however, Wilson speaks as an idealist, generally glossing over the problem of how technologies mediate and impact the relationship between people, on the one hand, and the circulation and constitution of knowledge, on the other. He did not analyze how knowledge organization structures (KO) could be effective for some people or some forms of knowledge, and ineffective for others, nor did he analyze similarly the constitutive components of $\mathrm{KO}$ as they relate to the differential effects on the use of knowledge. We posit that pluralistic modes of understanding $\mathrm{KO}$ are a fruitful way forward for the discipline. This paper conceptualizes how we can build on Wilson's critical conversations about epistemology in the domain of KO from three specific angles: $\mathrm{KO}$ as pluralized space, a political economy of $\mathrm{KO}$, and $\mathrm{KO}$ and political pragmatics.
\end{abstract}

\section{Introduction}

Patrick Wilson's writings have proven to be the foundation for much of our thinking about the organization of documents and their subtle connection to power structures that govern their construction and use (Wilson, 1968). Wilson had much to say as well about epistemology and how we can understand the nuanced relationships between public versus private knowledge (Wilson, 1977). Public knowledge, private ignorance: Toward a library and information policy (1977) makes the claim that, despite the wealth of public knowledge available, most decisions are asserted based on unreliable information, as most individuals use second-hand knowledge (Wilson, 1983), personal documents, and biased (and usually, faulty) memories (1977, pp. 35-44). Wilson sees the library and librarians as a remedy to this 'private ignorance.' In part, this ideal library service would rely on a complete library (1977, p. 87), and a complete understanding of the bibliographical instruments that organize these documents (Wilson, 1968, Chapter 4).

As presented here, in this synopsis, Wilson is speaking as an idealist. As laudable as it is, such a model is associated with a few assumptions regarding knowledge:

- all people possess the ability to access and use knowledge

- the nature of public knowledge is generally reliable, free of error, and bias

- the mediation of access to knowledge is also free of error and bias

The reality of the contemporary situation, however, is that the above assumptions no longer hold true, especially given the extent to which instruments of access (catalogs, search engines, etc.) are mediated by technologies that are far removed from public intervention, rendering their mechanisms invisible. If one were to identify a simplified version of most access scenarios in-line with Wilson's oeuvre, we could imagine a schematic that includes these three upper-level domains, 
Robert D. Montoya and Gregory H. Leazer. 2019. Public Knowledge, Private Ignorance, and an Analytic of Knowledge Organization. NASKO, Vol. 7. pp. 174-182.

- The domain of people (individuals, personal and social relationships, etc.)

- The domain of knowledge organization (KO)

- The domain of knowledge (as contained in, extrapolated from, and distributed by and through information, documents, and bibliographical objects)

Patrick Wilson focused on a critical analysis of the first and third areas - that of people and knowledge — but did not apply the same analytic to the domain of KO. Regarding people, some people have better access to knowledge by being better positioned to take advantage of reliable information, while others are poorly positioned to evaluate good information or gain access to it. Similarly, some forms of knowledge and information are more reliable that others, and the different kinds of information are not equally distributed across various social formations. However, this kind of analytic is missing from Wilson's treatment of KO. While Wilson was generally deflationary and skeptical of the role of $\mathrm{KO}$ and whether it could accomplish its objectives, he did not analyze how KO could be effective for some people or some forms of knowledge, and ineffective for others, nor did he analyze similarly the constitutive components of $\mathrm{KO}$ as they relate to the differential effects on the use of knowledge. We posit that pluralistic modes of understanding $\mathrm{KO}$ are a fruitful way forward for the discipline.

\section{Use of knowledge}

According to Wilson, public knowledge is a "common possession," and that "the use and benefits of which should be available not to a restricted few but to [humankind] generally" (1977, p. 121). So, while people possess the theoretical ability to access - and perhaps an ethical entitlement to - information, they often lack the ability to assess, negotiate, and verify the information that they are provided. Further, impersonal information sources often are financially costly (subscription-based journals for example, require institutional membership to access) (1977, p. 54), meaning that access is often restricted by our economic circumstances. It is these fundamental access-oriented challenges that prompt Wilson to emphasize the importance of libraries and librarians. Of course, with the rise of information systems and database-based documents, we are mediating much more than bibliographical objects, but data objects in general.

Knowledge, properly defined on an individual level, is true belief (Wilson, 1977, p. 6). True belief is, in part, based on properly evaluating public documents to make conclusions about the world. Evaluating documents depends on our ability to relate them with other documents within a system.

\section{Nature of knowledge}

Knowledge is as much a social object as it is a construct for individual people. For Wilson, knowledge is gained through both documentary and social means-and it is a mixture of these two sources that allows one to conclude the reliability or unreliability of information. As defined by Jesse H. Shera, social epistemology is the study of "function of recorded information in the actual working of society" (Shera, 1965, p. ix), and lies at the heart of the discipline of Information Studies, focused as it is on the "intellectual products" (Egan \& 
Robert D. Montoya and Gregory H. Leazer. 2019. Public Knowledge, Private Ignorance, and an Analytic of Knowledge Organization. NASKO, Vol. 7. pp. 174-182.

Shera, 1952, p. 132; quoted by Furner, 2004, p. 793) of a discipline and its subsequent organization into graphical mediums of communication to satisfy individual and group “epistemic needs" (Fuller, 2009, p. 4799). Patrick Wilson's (1983) extended investigation into cognitive authority gives a sense of how knowledge circulates within social spaces, how such knowledge is legitimated, and finally, how it is accessed within systemic access environments. Much of our information is gathered through our interpersonal networks. This information collected through social networks, as Wilson makes clear, is heavily weighted in decision-making, yet the weight it is afforded does not necessarily reflect the quality of knowledge it represents.

Reinvigorating Discussion of KO on Wilson's Terms: Mediation of access to knowledge As Bruce Shuman (1978) identified, in Public Knowledge Wilson did not broach how "questions of technology" (Wilson, 1977, p. viii) might impact our use of public knowledge, particularly how technology shape and limit our ability to access public knowledge.

Transparent knowledge organization systems are vital to decreasing private ignorance. In 1968, ten years prior to the publication of Public Knowledge, Wilson focused specifically on the question of access to knowledge in Two Kinds of Power (1968). In it, Wilson describes how an ideal bibliographical instrument would be one that is understandable and navigable by a user. Wilson states, "to discover what I can or might do if I would, I must discover the arrangements there are of which I can take advantage ... I cannot make the distinction accurately, however, without knowledge of the Specifications of the instrument, the rules according to which it was constructed" (1968, pp. 55, 59). In Wilson's conception, an instrument is the apparatus within which documents (broadly construed) are contained. An assessment of methods of access to knowledge--including for example, user assessments of document relevance--means understanding the limitations of the instruments that mediate our access to information.

This view of the "bibliographical instrument," while extended, is (1) speculative in nature, and (2) depends upon the possibility that an instrument can be enumerated in terms of available positions and social roles, for example (1968, p. 63). The archetypical catalog and encyclopedia are used as primary examples. And while there is a tacit acknowledgement that the growth of the instrument is an inevitability $(1968$, p. 63), the near-endless bounds of something akin to Google's documentary index is beyond the model constructed. Mechanical classification - and especially mechanized classification through computation —is not really Wilson's focus. People are still very much seen at the center of instrumental activity: "By automatic, or mechanical selection' I do not, of course, mean selection by a machine, but the selection that can be done by people in a mechanical, 'machine like' way." $(1968$, p. 62). These limitations have a deep impact on whether or not public knowledge can be achieved properly within individual realms of knowledge discovery and processing.

This gap in Wilson's analysis leaves room to expand his analysis, especially when we look toward the changes in contemporary circumstances and the 'instruments' that define our new and distributed notions of information and documentary access. Technologies of all types need to analyzed in light of this new analytic, including and especially algorithms, which 
Robert D. Montoya and Gregory H. Leazer. 2019. Public Knowledge, Private Ignorance, and an Analytic of Knowledge Organization. NASKO, Vol. 7. pp. 174-182.

have become a nearly-ubiquitous, and equally (and dangerously) silent, aspect of our social landscape.

\section{Extending Wilson's Critique}

In addition to his framework of users/KO/knowledge, we see in Wilson as a precursor to a more overt social and political analysis of the three domains. Within the realm of users, some people are better positioned to take advantage of systems of knowledge, because they have better informed social networks, or are able to make use of the mechanisms of access to knowledge. While he has not yet come to the full realization of mapping such an analytic to larger social formations like race, gender and class, he has begun the analytic that not all individuals bear equal status in access and the use of knowledge. For example, evolving concepts of epistemic justice (e.g. Fricker 2007) emphasize a "distributive unfairness" in epistemic goods such as when "interpretive [cognitive] resources put someone at an unfair disadvantage when it comes to making sense of their social experiences." Before emphasizing a political economy to the distribution of knowledge, we must first acknowledge that not everyone is equally capable of using information, due to inherent unfairness in educational systems, among other structural inequalities. As an additional example, there are competing models of knowledge use, such as those made apparent in consumerist vs. participatory relations to culture (for example, Postman 1985 vs. Jenkins 2006).

Wilson provides an early analytic of knowledge as well, providing a beginning for a fullblown critique. For example, his distinction between public and private knowledge also incorporates the notion of reliability: private knowledge, for example, is susceptible, characterized as unreliable and incomplete. The title of the 1977 book, after all, contrasts the vices of private ignorance with the positive virtues of public knowledge. Wilson should be credited for an early initial foray in the structure of knowledge, which opens up the possibility of further critique within KO. Such a critique could account for gaps, contradictions, and other vices within shared knowledge, like in Althusser's slightly earlier work. According to Althusser (1971, p. 153), knowledge can be hegemonic, encoding ideological operations that mask the true nature of the individual to his or her reality. Less explicitly political characterizations of shared knowledge include Swanson's 1986 work on "undiscovered public knowledge" where he characterizes knowledge as a puzzle whose pieces are independently constructed and assembled to reveal "an unseen, unknown and unintended pattern" (p. 103). Given the mismatch between the size and growth of knowledge, and limited ability of any one person to read even a fraction of printed books, public knowledge is accurately represented less as an assembled puzzle revealing previously unseen but shared patterns, and is more like a Rorschach test of shifting and resequenced elements revealing unstable and privately interpreted patterns.

Wilson's critique of $\mathrm{KO}$ is at a comparatively simpler stage. He problematizes it with a general tone of deflation in the sense that mechanisms and systems of access often underperform. He notoriously called their use "stupid": "The use of bibliographical instruments is frequently a stupid activity, as is, I suspect, known more or less clearly to many scholars, and provides an excellent reason why they should not do more of it" (1968, 
Robert D. Montoya and Gregory H. Leazer. 2019. Public Knowledge, Private Ignorance, and an Analytic of Knowledge Organization. NASKO, Vol. 7. pp. 174-182.

p. 118). His focus was on standard bibliographic apparatuses, such as catalogs, indices, and traditionally constructed classifications. He did not look at the particular roles of language or technology as constituting $\mathrm{KO}$, or how alternative models of either could lead to alternative constructions of KO.

An example of a conceptual tool of analysis that Wilson did use was that of transparency-that the effective use of KO tools was predicated on the users' comprehension of the tools' design and appropriate use. This is a critical concept in the analysis of contemporary KO tools, particularly in the assessment of the use of algorithms in KO. Increasingly, classification systems that utilize algorithmic means of organization make it difficult to evaluate the methods by which they organize documents. Safiya Noble's analysis of Google is a case in point: search engine users, when seeking out words such "black girls" were given sexualized and pornified results. Such a circumstance means that public perception of black identity is directed to racist and sexualized conceptions.

We also see a great deal of problems in the biological world, where large-scale data is automatically organized into taxonomies that are then used to browse and contextualize the data they contain. We can take the Global Biodiversity Information Facility (GBIF) (GBIF, 2017) as a prime example. GBIF is the world largest aggregator of biological data, currently containing well over one-billion species occurrence records. Dealing with taxonomic data at these scales, it is unreasonable to expect human curation for every data record. In order to make these data available, GBIF has created their Nub Taxonomy (2016), which is designed to serve as the backbone $\mathrm{KO}$ architecture for their system. As new species occurrence data is ingested into GBIF, the data is algorithmically cleaned and reconciled to a form that is GBIF compliant. It is occasionally the case, that during this process, species data is incorrectly processed, leading to classification errors. As Robert Mesibov has identified, species data can be deleted altogether, up-matched (placed into a higher taxonomic rank than it should be), or down-matched ("when a name is particularised ... at a level in the taxonomic hierarchy below the supplied or appropriate one"). The result of these algorithmicallyintroduced errors is that documents cannot be properly assessed at the point of access.

In both Google's presentation of "black girls" and the algorithmic grouping of biological taxa, the classification is created by an obscured technological system that poses as neutral. The lack of transparency is an issue because it becomes difficult to assess the criteria by which objects (documents, web pages, organisms, etc.) are grouped. Certainly, the lack of transparency in automated systems is a shortcoming that interferes with their effective use, and Wilson's notion of transparency is a useful related concept. However, we would see a clearer through-line connecting Wilson to current critiques of the role of algorithms in classificatory systems if Wilson had used the concept as part of an analytic critique of KO, for example, if he differentiated amongst systems as more or less transparent due to their particular use of technology or language.

\section{Plurality}

However, we do see Wilson as one source for understanding users, $\mathrm{KO}$ and knowledge as pluralized spaces. His work presents a nuanced view of both the social construction of 
Robert D. Montoya and Gregory H. Leazer. 2019. Public Knowledge, Private Ignorance, and an Analytic of Knowledge Organization. NASKO, Vol. 7. pp. 174-182.

knowledge, as well as the variety of bibliographical works that constitute our various sources of information. If one looks closely we can begin to see how Wilson is constructing a social and documentary epistemology based on a network of ideas and perspectives - a plurality of positionality, perspective and voice. Wilson's notion of social epistemology in Public Knowledge, Private Ignorance (1977), for example, shows how the generation of "truth" with regard to individual opinion or decision-making is based on an interconnected set of social relations. These relationships necessarily complicate judgement through the various opinions and interpretations of many individuals. Further, these opinions are intricately related to structures of power such social occupations and other culturally-established distributions of knowledge (1977, pp. 45-52). One need only look at the daily headlines today to see how 'plural' our spaces our: turn to Fox News, on the one hand, and the Washington Post, on another. As such, knowledge, is derivatively also nuanced, given that they are also plural and multivocal. Cognitive authority and decision-making are complex and nuanced, and even more so in our contemporary environment.

Other scholars, such as Hope Olson and Birger Hjørland commit to a similar sense of social pluralism. Olson's feminist critique of subject construction (2008), for example, show how a traditional Aristotelian, linear, and hierarchical method of classification exclude minoritized positions in accessing knowledge. Olson posits a web-based (and somewhat pragmatic) network over such models. Referencing Blythe McVicker Clinchy's scholarship, Olson indicates that networked, connected knowledge lies midway between objective and subjective ways of knowing: "connected knowing avoids the adversarial practices of traditional philosophy that focus on objectivity and validity, but it does maintain the notion of a singular concept of truth" (2008, p. 525). But even so, the ultimate aim for Olson's feminist intervention is to highlight the rejection of 'one' singular truth and to design $\mathrm{KO}$ structures that represent the social relationships that contribute to our belief structures. Though not network focused, Hjørland's notion of domain analysis is useful in this respect. Domain analysis is a method of understanding KO structures as emerging from "discourse communities" (Hjørland \& Albrechtsen, 1995). Such an approach focuses explicitly on the social perspectives in that it pushes for community-specific KO, but it also supports interdisciplinary comparison to identify commonalities between different domains. This comparative approach similarly highlights the extent to which looking at "social" notions of classification and organization is tantamount to looking at many ways of understanding the world.

Extending this notion, we can look to scholars outside of the information and KO community for similar expressions, for example, Thomas Khun's paradigm model of knowledge (1996). A paramount idea in Kuhn's text comes from the use of the term "structure "in the title of his book: the notion that collective knowledge evolves through identifiable modes and mechanisms - from normality to revolution, knowledge is inherently a social mechanism that is facilitated through a network of tools and mediating documents. Once again, at the core of Kuhn's theory is, in part, comparative. Many communities circulate within scientific circles and these communities, but even so, there is a flow of information between them: "the historian must compare the community's paradigms with each other and 
Robert D. Montoya and Gregory H. Leazer. 2019. Public Knowledge, Private Ignorance, and an Analytic of Knowledge Organization. NASKO, Vol. 7. pp. 174-182.

with its current research reports. In doing so, his object is to discover what isolable elements, explicit or implicit, the members of that community may have abstracted from their more global paradigms and deployed as rules in their research" (1996, pp. 43-44). Structure, then, plays an equally-important role in the realm of $\mathrm{KO}$, and so examining paradigmatic trends comparatively can help us understand how certain regimes challenge the epistemic authority of systems that are meant to provide single access points for inherently plural spaces.

The end result is that Wilson sets the ground for subsequent examinations that acknowledge there are many knowledge domains that we must attend to in both the domain of people and the domain of knowledge. So, too, must we examine KO structure as inhabiting similar notions of pluralism - or perhaps, more appropriately, imagine new systems and theories that embody these values. To this end, we see three-part analytic for understanding user, $\mathrm{KO}$, and knowledge. In the first and third of those areas, the analytic extends a conversation initiated in part by Wilson, and one that can be extended to KO proper. Our analytic conceptualizes that can build on Wilson's conversation: $\mathrm{KO}$ as pluralized space, a political economy of $\mathrm{KO}$, and $\mathrm{KO}$ and political pragmatics.

Pluralized spaces.

Perhaps one of the more advanced discussions in our domain is the idea that technologies are spaces of multi-vocal arrangements. Not only do communities have their own mechanisms of KO, but even within those spaces, perspectives differ and we must attend to these differences by arranging new modes of description, metadata application, classifying and linking in open environments.

\section{Political economy.}

Within any KO system, domain- or community-centric or otherwise, there are political economies with which to contend. Wilson made this connection when examining modes of cognitive authority as being integrally tied to institutional arrangements. Certain ideas, concepts, and individuals are prioritized over others based on economic, political, and social standing. This invariably means that the means for distributive and recognitional justice (Mathiesen, 2015) fall short. To this end, community members must also have a mechanism for changing existing systems to attend to their individual and community needs-Kay Mathiesen (2015, p. 208) highlights this form of "participatory justice" as it relates to information access.

\section{Political pragmatics.}

Attending to the theoretical concerns of political economies of $\mathrm{KO}$ is one thing, but there are also practical mechanisms at work that enact certain political agendas. If one were to look at systems such as Google, Facebook, and Twitter we can see there are clear patterns of power at work. The ability for certain right-wing organizations to circulate unreliable information (unfactual, deceiving information) is a particular way in which the economy of our $\mathrm{KO}$ and information environments are being pointed in specific directions. Certain epistemic communities rise to the top, while others consistently stay on the margins. 
Robert D. Montoya and Gregory H. Leazer. 2019. Public Knowledge, Private Ignorance, and an Analytic of Knowledge Organization. NASKO, Vol. 7. pp. 174-182.

\section{Conclusion}

As a scholar of his time, Wilson would have certainly been concerned with the distribution of educational and information services, particularly in the institutional manifestations such as schools and libraries. As the events of 2016 have made abundantly clear, the notion of contested facts and the role of disinformation--concerns that certainly predate the US Presidential election--are now made apparent on a daily basis. We hope to explore the shifting nature of the demarcation and interactions between public knowledge and private knowledge, how the interplay between the two is now explicitly political and mediated by uncertain computational mechanisms, and is a central element in the political contest of the constitution of the public sphere and civil society itself.

\section{References}

Althusser, L. (1971). Ideology and Ideological State Apparatuses. Lenin and Philosophy and other Essays. pp. 121-176.

Egan, M. E., and J. H. Shera (1952). Foundations of a Theory of Bibliography. Library Quarterly 22: $125-137$.

Fricker, A. (2007). Epistemic injustice: power and the ethics of knowing. Oxford University Press.

Fuller, S. (2009). Social Epistemology. In M. N. Maack \& M. Bates (Eds.), Encyclopedia of Library and Information Sciences 3rd ed. CRC Press.

GBIF. (2017). GBIF. Retrieved October 1, 2015, from Global Biodiversity and Information Facility website: http://www.gbif.org/

Global Biodiversity and Information Facility. (2016). GBIF backbone taxonomy. Retrieved from GBIF.org website: https://www.gbif.org/dataset/d7dddbf4-2cf0-4f39-9b2a-bb099caae36c

Hjørland, B., \& H. Albrechtsen (1995). Toward a new horizon in information science: Domainanalysis. Journal of the American Society for Information Science 46(6): 400-425.

Jenkins, H. (2006). Confronting the Challenges of Participatory Culture: Media Education for the 21st Century. Chicago: John D. and Catherine T. MacArthur Foundation.

Kuhn, T.S. (1996). The Structure of Scientific Revolutions (3rd ed). Chicago, IL: University of Chicago Press.

Mathiesen, K. (2016). Informational Justice: A Conceptual Framework for Social Justice in Library and Information Services. Library Trends, 64(2): 198-225. https://doi.org/10.1353/lib.2015.0044

Mesibov R. (2018) An audit of some processing effects in aggregated occurrence records. ZooKeys 751:129-146. https://doi.org/10.3897/zookeys.751.24791

Noble, S. (2018). Algorithms of Oppression: How Search Engines Reinforce Racism. New York: NYU Press.

Postman, N. (1985). Amusing Ourselves to Death: Public Discourse in the Age of Show Business. Penguin.

Shera, J. H. (1965). Libraries and the organization of knowledge. Hamden, Connecticut: Archon Books.

Shuman, B. A. (1978). Book review of Wilson, P., Public knowledge, private ignorance: Toward a library and information policy. Westport, CT: Greenwood Press; 1977. Journal of the American Society for Information Science 29(3): 167-168. https://doi.org/10.1002/asi.4630290317

Swanson, D. (1986). Undiscovered public knowledge. Library Quarterly 56: 103-118.

Olson, H. A. (2008). How We Construct Subjects: A Feminist Analysis. Library Trends. 56(2), 509541. https://doi.org/10.1353/lib.2008.0007 
Robert D. Montoya and Gregory H. Leazer. 2019. Public Knowledge, Private Ignorance, and an Analytic of Knowledge Organization. NASKO, Vol. 7. pp. 174-182.

Wilson, P. (1968). Two kinds of power; an essay on bibliographical control. Berkeley: University of California Press.

Wilson, P. (1977). Public knowledge, private ignorance: toward a library and information policy. Westport, Conn: Greenwood Press.

Wilson, P. (1983). Second-hand knowledge: an inquiry into cognitive authority. Westport, Conn: Greenwood Press. 